\title{
Revamping Grooving Process for Sustainability using Fuzzy Expert System
}

\author{
Asif lqbal \\ Department of Mechanical \& Aerospace Engineering, Air University, Islamabad, Pakistan
}

\begin{abstract}
The article presents an application of a fuzzy expert system for renovating a metal cutting process to cope with the sustainability requirements. The work seeks a sustainable balance between energy consumption, productivity and tool damage. Cylindrical grooving experiments were performed to generate data related to quantification of the effects of material hardness, cutting speed, width of cut and feed rate on the aforementioned sustainability measures. A fuzzy knowledge-base was developed that suggests the most suitable adjustments of the controlled variables that would lead to achievement of various combinations of the objectives.
\end{abstract}

\section{Introduction}

For last 15 years or so, manufacturing processes are being readjusted in accordance with the environmental benignity requirements. The quest of the current research activities is to reduce negative environmental impacts by finding ways to lift productivity and curb consumption of energy and other natural resources. The metal cutting processes, thus, are under intense study for embracing sustainability norms.

An analytical method for minimizing process cost and energy consumption for machining process was presented [1]. The method searches for a cutting speed value that guarantees longest tool life and minimum energy cost. Diaz et al have compared demand of power in micromachining of steel with those of polycarbonate and aluminum at various productivity levels [2]. The authors in another work have presented a multi-objective analysis of energy consumption, process cost, and work surface roughness of a machining process based on optimization of cutting speed, feed rate, and depth of cut [3]. In a recent work, a comparison between tool life, process cost, productivity, and specific energy consumption has been provided [4]. Another work presents a model that optimizes cutting parameters for maximization of profit per unit energy consumption in a single pass turning process [5]. A mathematical model was put forward that quantifies energy requirements in three different states of machining for various machines [6]. In [7], the authors have presented an experimental investigation for energy cost modeling of turning hard steel. The authors have used Box-Behnken Design and artificial neural networks for the modeling purpose.

With regard to application of intelligent systems, Hashmi et al have developed a fuzzy knowledge-based system for optimization of cutting speed as a function of work hardness based on various combinations of work material, depth of cut and tool material [8]. A prediction model for surface roughness and thrust force for a drilling process was developed using radial basis function network [9]. A fusion of fuzzy logic, neural network, and genetic algorithm was presented for optimizing parameters of a turning process [10]. A self-developing fuzzy expert system capable of modeling and optimizing manufacturing process without requirement of manually developing fuzzy sets or rules was presented [11]

The current work presents a fuzzy expert system developed from experimental data generated through cylindrical grooving experiments performed on a highstrength low alloy steel. The aim of the expert system is to revamp the grooving process in accordance with the requirements of manufacturing sustainability, such as minimize specific energy consumed, maximize productivity (in terms of material removal rate), and maximize tool life.

\section{Experimental work}

Four predictor variables were controlled in a fullfactorial, mixed level design of experiments. The process of cylindrical grooving was studied on a high-strength low alloy steel, AISI 4340. Cylindrical grooving was selected because it is a metal cutting process that most closely matches an orthogonal cutting process. Following is the detail of the input parameters (predictor variables):

1. Work material hardness, $H$. The material rods were heat-treated differently to obtain two levels of hardness: 31 and 38 HRc.

2. Cutting speed, $V_{\text {c. }}$ Three levels were tested: 28,57 , and $89 \mathrm{~m} / \mathrm{min}$ 


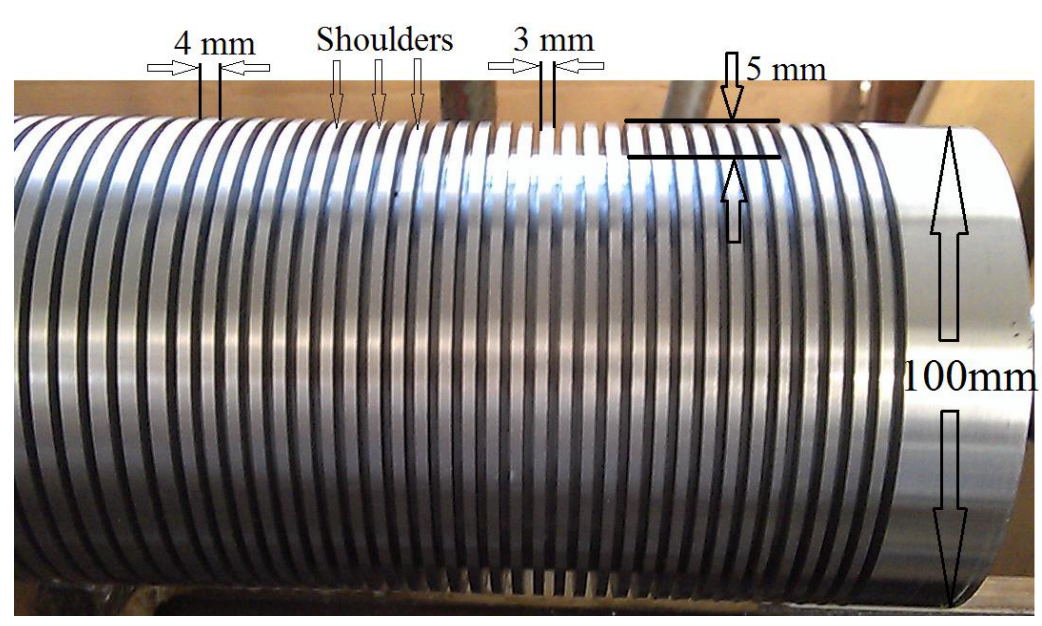

(a)

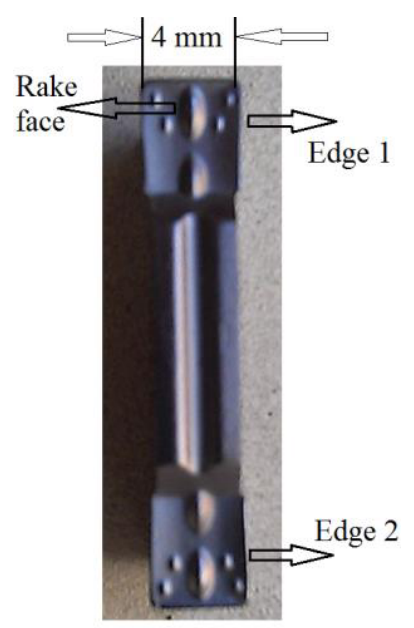

(b)

Figure 1. Experimental setup: (a) an AISI 4340 rod with shoulders cut into its surface; (b) a grooving insert

3. Feed rate, $f$. Two levels were used: 0.07 and 0.17 $\mathrm{mm} / \mathrm{rev}$.

4. Width of cut, $w(\mathrm{~mm}) . w$ was controlled by the following three widths of cutting inserts used: 2,3 , and $4 \mathrm{~mm}$.

The number of the levels of the four predictors suggest that $36(=2 \times 3 \times 2 \times 3)$ experiments were conducted in total. All the experimental runs were conducted on a CNC lathe with a maximum spindle speed $3500 \mathrm{rpm}$ and maximum motor power $11 \mathrm{~kW}$. The AISI 4340 material was used in the form of rods having length $500 \mathrm{~mm}$ and diameter $100 \mathrm{~mm}$. Before start of the experiments, 108 (= 36 experimental runs $\times 3$ ) cylindrical shoulders of $5 \mathrm{~mm}$ depth and 2, 3, and $4 \mathrm{~mm}$ widths were prepared on the bars. The widths of the shoulders correspond to the widths of the inserts chosen. Figure 1 gives the details. Uncoated tungsten carbide cutting inserts having flank angle $12^{\circ}$ and rake angle $1.5^{\circ}$ were used. Each of the 18 inserts (each insert has 2 cutting edges) was required to cut 3 relevant shoulders. The area of material removed (AMR) in cutting each shoulder is $1492.3 \mathrm{~mm}^{2}\left[=\pi\left\{(50)^{2}\right.\right.$ - $\left.\left.(50-5)^{2}\right\}\right]$ and for three shoulders is $4477 \mathrm{~mm}^{2}$. The total volume of material removed by each insert of 2,3 , and $4 \mathrm{~mm}$ width is $8954(=2 \times 4477), 13431$, and 17908 $\mathrm{mm}^{3}$, respectively. The flank wear was measured, using $10 \times$ toolmaker's microscope, after cutting each of the three assigned shoulders. The three wear levels are denoted by $V B 1, V B 2$, and $V B 3$. Material removal rate $M R R\left(\mathrm{~mm}^{3} / \mathrm{sec}\right)$ was calculated by using the relationship: $M R R=w \times f \times\left(V_{\mathrm{c}} / 60 \times 1000\right)$.

The following responses were assessed for each run:

1. Width (maximum) of wear land on flank face of the tool after cutting each of the three shoulders, $V B 1$, $V B 2$, and $V B 3(\mathrm{~mm})$.

2. Total energy consumed in cutting of three shoulders, $E(\mathrm{~kJ})$.

3. Specific cutting energy, $S E\left(\mathrm{~J} / \mathrm{mm}^{3}\right)$. The $S E$ is evaluated by dividing average cutting power by $M R R$.
Electric power drawn by the machine tool was measured by applying Fluke 345 on its power cable. The noncutting electric power used up by the lathe, for each of the $6(=3 \times 2)$ combinations of feed and cutting speed, was found out by revolving a rod and advancing the tool inwards at the given combination of the cutting parameters, but without touching the rod. The actual cutting power was evaluated by lessening the total power measured during the cutting process from the relevant non-cutting power. The cutting power was then averaged and multiplied with the relevant cutting time to obtain the value of $E$ for each experiment.

\subsection{Experimental results}

Table 1 shows the results for the 36 runs. Few observations can directly be extracted from the table: (1) the higher levels of cutting speed, width of cut and feed rate render higher magnitude of tool damage; (2) cutting of the harder temper causes higher magnitude of tool damage; (3) Higher levels of speed, feed, and width of cut cause slash in specific cutting energy; and (4) the harder temper of material causes rapid tool damage as well as more consumption of specific energy.

\section{Development of the fuzzy expert system}

\subsection{Data fuzzification}

Triangular fuzzy sets were worked out for the predictors and responses. As the predictors are user controlled, their membership functions are evenly distributed. On the other hand, the experimental values of the responses are not distributed evenly or even randomly; their distributions show existence of two to three dense zones. For the sets related to the response variables, the dense zones are assigned more membership functions than the rare areas. 
Table 1. The experimental results.

\begin{tabular}{|c|c|c|c|c|c|c|c|c|c|c|}
\hline $\begin{array}{c}\text { S/ } \\
\text { No. }\end{array}$ & $\begin{array}{c}H \\
\text { (HRc) }\end{array}$ & $\begin{array}{c}V_{\mathrm{c}} \\
(\mathrm{m} / \mathrm{min})\end{array}$ & $\begin{array}{c}f \\
(\mathrm{~mm} / \mathrm{r})\end{array}$ & $\begin{array}{c}w \\
(\mathrm{~mm})\end{array}$ & $\begin{array}{c}V B 1 \\
(\mathrm{~mm})\end{array}$ & $\begin{array}{c}V B 2 \\
(\mathrm{~mm})\end{array}$ & $\begin{array}{c}V B 3 \\
(\mathrm{~mm})\end{array}$ & $\begin{array}{c}E \\
(\mathrm{~kJ})\end{array}$ & $\begin{array}{c}M R R \\
\left(\mathrm{~mm}^{3} / \mathrm{sec}\right)\end{array}$ & $\begin{array}{c}S E \\
\left(\mathrm{~J} / \mathrm{mm}^{3}\right)\end{array}$ \\
\hline 1 & 31 & 28 & 0.07 & 2 & 0.02 & 0.049 & 0.057 & 282.9 & 65.97 & 6.32 \\
\hline 2 & 31 & 28 & 0.07 & 3 & 0.028 & 0.051 & 0.065 & 278.7 & 98.96 & 4.15 \\
\hline 3 & 31 & 28 & 0.07 & 4 & 0.036 & 0.058 & 0.078 & 360.8 & 131.95 & 4.03 \\
\hline 4 & 31 & 28 & 0.17 & 2 & 0.053 & 0.059 & $\begin{array}{l}0.069 \\
\end{array}$ & 125.8 & 160.22 & 2.81 \\
\hline 5 & 31 & 28 & 0.17 & 3 & 0.043 & 0.061 & 0.092 & 165.2 & 240.33 & 2.460 \\
\hline 6 & 31 & 28 & 0.17 & 4 & 0.045 & 0.071 & 0.097 & 163 & 320.44 & 1.820 \\
\hline 7 & 31 & 57 & 0.07 & 2 & 0.032 & 0.042 & 0.066 & 353.2 & 131.95 & 7.890 \\
\hline 8 & 31 & 57 & 0.07 & 3 & 0.032 & 0.055 & 0.072 & 325 & 197.92 & 4.840 \\
\hline 9 & 31 & 57 & 0.07 & 4 & 0.041 & 0.062 & 0.082 & 357.2 & 263.9 & 3.990 \\
\hline 10 & 31 & 57 & 0.17 & 2 & 0.047 & 0.055 & 0.08 & 156.2 & 320.44 & 3.490 \\
\hline 11 & 31 & 57 & 0.17 & 3 & 0.039 & 0.055 & 0.0457 & 187.4 & 480.66 & 2.790 \\
\hline 12 & 31 & 57 & 0.17 & 4 & 0.055 & 0.076 & 0.112 & 146.8 & 640.89 & 1.640 \\
\hline 13 & 31 & 89 & 0.07 & 2 & 0.041 & 0.067 & 0.079 & 233.2 & 207.8 & 5.210 \\
\hline 14 & 31 & 89 & 0.07 & 3 & 0.041 & 0.067 & 0.084 & 296.8 & 311.73 & 4.420 \\
\hline 15 & 31 & 89 & 0.07 & 4 & 0.044 & 0.072 & 0.095 & 368 & 415.63 & 4.110 \\
\hline 16 & 31 & 89 & 0.17 & 2 & 0.045 & 0.053 & 0.088 & 110.1 & 504.7 & 2.460 \\
\hline 17 & 31 & 89 & 0.17 & 3 & 0.028 & 0.044 & 0.0437 & 165.2 & 757.05 & 2.460 \\
\hline 18 & 31 & 89 & 0.17 & 4 & 0.06 & 0.084 & 0.132 & 135.2 & 1009.4 & 1.510 \\
\hline 19 & 38 & 28 & 0.07 & 2 & 0.024 & 0.054 & 0.078 & 346.1 & 65.97 & 7.730 \\
\hline 20 & 38 & 28 & 0.07 & 3 & 0.034 & 0.066 & 0.092 & 331.7 & 98.96 & 4.940 \\
\hline 21 & 38 & 28 & 0.07 & 4 & 0.043 & 0.075 & $\begin{array}{l}0.108 \\
\end{array}$ & 410.1 & 131.95 & 4.580 \\
\hline 22 & 38 & 28 & 0.17 & 2 & 0.062 & 0.076 & 0.099 & 166.1 & 160.22 & 3.710 \\
\hline 23 & 38 & 28 & 0.17 & 3 & 0.052 & 0.082 & 0.127 & 216.2 & 240.33 & 3.220 \\
\hline 24 & 38 & 28 & 0.17 & 4 & 0.062 & 0.092 & $\begin{array}{l}0.128 \\
\end{array}$ & 252.5 & 320.44 & 2.820 \\
\hline 25 & 38 & 57 & 0.07 & 2 & 0.038 & 0.057 & 0.088 & 367.1 & 131.95 & 8.200 \\
\hline 26 & 38 & 57 & 0.07 & 3 & 0.041 & 0.075 & $\begin{array}{l}0.099 \\
\end{array}$ & 392.2 & 197.92 & 5.840 \\
\hline 27 & 38 & 57 & 0.07 & 4 & 0.049 & 0.080 & 0.115 & 442.3 & 263.9 & 4.940 \\
\hline 28 & 38 & 57 & 0.17 & 2 & 0.056 & 0.071 & 0.110 & 186.2 & 320.44 & 4.160 \\
\hline 29 & 38 & 57 & 0.17 & 3 & 0.047 & 0.071 & 0.088 & 235.7 & 480.66 & 3.510 \\
\hline 30 & 38 & 57 & 0.17 & 4 & 0.065 & 0.098 & $\begin{array}{l}0.155 \\
\end{array}$ & 180.0 & 640.89 & 2.010 \\
\hline 31 & 38 & 89 & 0.07 & 2 & 0.048 & 0.0864 & $\begin{array}{l}0.104 \\
\end{array}$ & 291.4 & 207.8 & 6.510 \\
\hline 32 & 38 & 89 & 0.07 & 3 & 0.049 & 0.083 & 0.116 & 347.2 & 311.73 & 5.170 \\
\hline 33 & 38 & 89 & 0.07 & 4 & 0.053 & 0.091 & $\begin{array}{l}0.128 \\
\end{array}$ & 445.9 & 415.63 & 4.980 \\
\hline 34 & 38 & 89 & 0.17 & 2 & 0.054 & 0.072 & 0.118 & 137.9 & 504.7 & 3.080 \\
\hline 35 & 38 & 89 & 0.17 & 3 & 0.034 & 0.057 & 0.093 & 208.2 & 757.05 & 3.100 \\
\hline 36 & 38 & 89 & 0.17 & 4 & 0.069 & 0.108 & $\begin{array}{l}0.182 \\
\end{array}$ & 165.6 & 1009.4 & 1.850 \\
\hline
\end{tabular}

A fuzzy version of CLIPS software was used for formulating the expert system. Following is presentation of the triangular fuzzy sets of the variables (input and output) in CLIPS format:

$\boldsymbol{H}$ : So $\{\operatorname{Soft}\}[(27,1)(31,1)(38,0)] ;$ Ha $\{\operatorname{Hard}\}[(31,0)(38,1)$ $(42,1)]$

$V_{\mathbf{c}}$ : Sl $\{$ Slow $\}[(21,1)(28,1)(57,0)] ;$ Me $\{$ Medium $\}[(28,0)$ $(57,1)(89,0)] ;$ Fa $\{$ Fast $\}[(57,0)(89,1)(96,1)]$

$f:$ Sm $\{$ Small $\}[(0.05,1)(0.07,1)(0.17,0)] ;$ La $\{$ Large $\}[(0.07$, $0)(0.17,1)(0.19,1)]$

$\boldsymbol{w}$ : Na $\{$ Narrow $\}[(1,1)(2,1)(3,0)] ;$ Me $\{$ Medium $\}[(2,0)(3$, 1) $(4,0)]$; Wi $\{$ Wide $\}[(3,0)(4,1)(5,1)]$

MRR: EVL $\{$ Extremely very low $\}[(50,1)(65,1)(120,0)] ; \mathbf{V L}$ $\{$ Very low $\}[(65,0)(120,1)(175,0)] ; \mathbf{L}\{$ Low $\}[(120,0)(200$, 1) $(250,0)]$; SL $\{$ Slightly low $\}[(200,0)(250,1)(300,0)]$; $\mathbf{S H}$ $\{$ Slightly high $\}[(250,0)(310,1)(370,0)] ; \mathbf{H}\{$ High $\}[(310,0)$ $(410,1)(500,0)] ; \mathbf{H}\{\mathrm{High}\}[(310,0)(410,1)(500,0)] ; \mathbf{V H}$ $\{$ Very high $\}[(410,0)(570,1)(730,0)]$; EVH $\{$ Extremely very high $\}[(520,0)(960,1)(1025,1)]$
VB3: EEL $\{$ Extremely extremely low $\}[(0.035,1)(0.05,1)$ $(0.065,0)]$; EVL $\{$ Extremely very low $\}[(0.05,0)(0.064,1)$ $(0.078,0)] ; \mathbf{V L}[(0.064,0)(0.074,1)(0.084,0)] ; \mathbf{L}[(0.074,0)$ $(0.082,1)(0.09,0)]$; SL $[(0.085,0)(0.09,1)(0.095,0)]$; SH $[(0.093,0)(0.098,1)(0.103,0)] ; \mathbf{H}[(0.1,0)(0.109,1)(0.118$, $0)] ; \mathbf{V H}[(0.11,0)(0.122,1)(0.134,0)] ; \mathbf{E V H}[(0.125,0)$ $(0.143,1)(0.161,0)]$; EEH $\{$ Extremely extremely high\} $[(0.145,0)(0.165,1)(0.185,1)]$

$\boldsymbol{E}: \mathbf{E E L}[(70,1)(100,1)(140,0)] ; \mathbf{E V L}[(100,0)(130,1)(160$, $0)]$; VL $[(135,0)(155,1)(175,0)] ; \mathbf{L}[(160,0)(175,1)(190$, $0)] ; \mathbf{S L}[(175,0)(200,1)(225,0)] ; \mathbf{S H}[(200,0)(240,1)(270$, $0)] ; \mathbf{H}[(240,0)(270,1)(300,0)] ; \mathbf{V H}[(270,0)(310,1)(350$, $0)]$; EVH $[(310,0)(355,1)(400,0)] ;$ EEH $[(360,0)(425,1)$ $(450,1)]$

SE: EEL $[(0.5,1)(1,1)(1.8,0)] ;$ EVL $[(1,0)(1.8,1)(2.6,0)] ;$ VL $[(1.8,0)(2.4,1)(3,0)] ; \mathbf{L}[(2.4,0)(3,1)(3.6,0)] ; \mathbf{S L}[(3$, $0)(3.5,1)(4,0)]$; SH $[(3.5,0)(4,1)(4.5,0)] ; \mathbf{H}[(4,0)(4.4,1)$ $(4.8,0)] ; \mathbf{V H}[(4.4,0)(5,1)(5.6,0)] ; \mathbf{E V H}[(4.8,0)(6.4,1)(8$, $0)]$; EЕH $[(6.4,0)(8.1,1)(9.5,1)]$ 


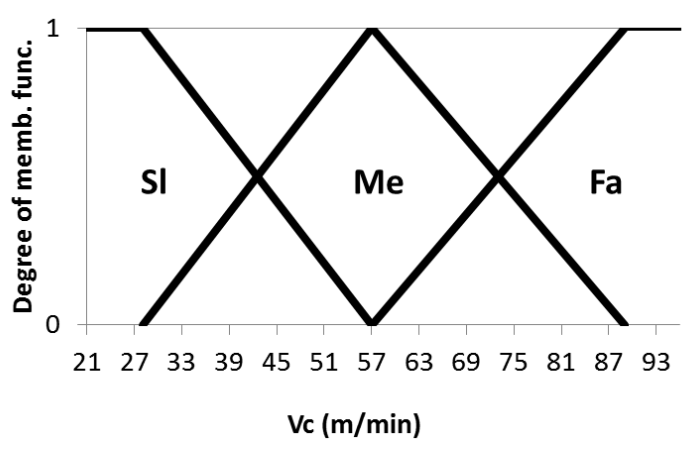

Figure 2. The triangular fuzzy set of $V_{\mathrm{c}}$.

For graphical description, the fuzzy set of cutting speed is presented in Figure 2.

\subsection{The optimization approach}

The aim of the expert system is to suggest the ideal values of the unfixed predictors (input variables) according to a given combination of the objectives. The process kicks off with the user's input of the desired objective(s) and values of the input parameters. It is compulsory to select an objective or a combination of objectives, while the four input parameters may or may not be fixed according to the problem on hand. Any of the following eight combinations can be chosen as the objective:

1. Minimize $E$

2. Minimize $V B 3$

3. Minimize $S E$

4. Min. $E$ and max. $M R R$, simultaneously

5. Min. $E$ and min. $V B 3$, simultaneously

6. Min. $V B 3$ and max. $M R R$, simultaneously

7. Min. VB3, minimize $E$, and $\max$. $M R R$, simultaneously

8. Min. $V B 3$ and min. $S E$, simultaneously.

Next comes fuzzification of the numeric values of the input parameters fixed by the user. Fuzzification is a process of converting format in which numeric data are changed into a lingual form, which is well understandable by human minds. Fuzzification of the experimental values is done according to the relevant fuzzy sets. The sequence of parameters optimization starts with fixing of $H$ and follows with that of $f, V_{\mathrm{c}}$, and $w$. The knowledgebase of the expert system is as follows:

1. IF $\boldsymbol{H}$ is unfixed THEN $\boldsymbol{H}$ is So.

2. IF $\boldsymbol{f}$ is unfixed and Objective is Minimize $V B 3$ THEN $\boldsymbol{f}$ is Sm ELSE $\boldsymbol{f}$ is La.

3. IF $\boldsymbol{V}_{\mathrm{c}}$ is unfixed and Objective is Minimize $V B 3$ or "Minimize $V B 3$ and Minimize $E$ " THEN $\boldsymbol{V}_{\mathbf{c}}$ is $\mathbf{S l}$ ELSE $\boldsymbol{V}_{\mathbf{c}}$ is $\mathbf{F a}$.

4. IF $\boldsymbol{w}$ is unfixed and Objective is "Minimize $V B 3$ and Maximize $M R R$ " or "Minimize $V B 3$ and Minimize $E$ and Maximize MRR" THEN $\boldsymbol{w}$ is Me\&Wi.
5. IF $\boldsymbol{w}$ is unfixed and Objective is Minimize $V B 3$ or Minimize $E$ or "Minimize $V B 3$ and Minimize $E$ " THEN $\boldsymbol{w}$ is Na.

6. IF $\boldsymbol{w}$ is unfixed and Objective is "Minimize $E$ and Maximize MRR" THEN $\boldsymbol{w}$ is Me.

" $\&$ " is a union operator (used in rule 4), which produces an amalgamated fuzzy value of two successive membership functions of a set.

The aforementioned rules are applicable to the objectives in which energy consumed is dealt in its absolute form, i.e., E. Following is the list of the rules in which energy consumed is presented in its specific form, i.e., $S E$.

1. IF $\boldsymbol{H}$ is unfixed THEN $\boldsymbol{H}$ is So.

2. IF $\boldsymbol{f}$ is unfixed THEN $\boldsymbol{f}$ is La.

3. IF $\boldsymbol{V}_{\mathbf{c}}$ is unfixed and Objective is Minimize $S E$ THEN $\boldsymbol{V}_{\mathbf{c}}$ is Fa ELSE $\boldsymbol{V}_{\mathbf{c}}$ is $\mathbf{S l}$.

4. IF $\boldsymbol{w}$ is unfixed and Objective is "Minimize $S E$ and Minimize VB3" THEN $\boldsymbol{w}$ is Me ELSE $\boldsymbol{w}$ is Wi.

The output of the optimization step is fuzzified values of the optimized input parameters in form of membership functions of the relevant fuzzy sets. In the last step, the fuzzy values of the optimized predictors are defuzzified to get numeric and distinct values. The process of defuzzification transforms a fuzzy value to a number that is most central to the fuzzy distribution.

\section{Application examples}

Two optimization examples, related to grooving of AISI 4340, are provided. Further experiments were performed at the optimized settings of the input parameters to find the values of the maximized/minimized output parameters.

In the first example, it is desired to find ideal values of cutting speed and width of cut for the following combinations of objectives: (a) minimize $S E \&$ minimize $V B 3$, simultaneously and (b) minimize $S E \&$ maximize $M R R$, simultaneously. The values of material hardness and feed rate are fixed as $33 \mathrm{HRc}$ and $0.14 \mathrm{~mm} / \mathrm{rev}$, respectively.

In the second example, it is desired to optimize cutting speed and feed rate for the following objectives: (a) minimize $V B 3$ and (b) minimize $S E$ and maximize $M R R$, simultaneously. The values of material hardness and width of cut are fixed as $36 \mathrm{HRc}$ and $3.5 \mathrm{~mm}$, respectively. Tables 2 and 3 present the optimization results and the measured values of the responses against the optimized values of the predictors for example 1 and 2, respectively.

The results suggest that energy consumption can be minimized by operating the machining process at the maximum levels of the cutting parameters, especially feed rate and cutting speed. Such a combination would also guarantee high level of productivity. 
Table 2. The optimization results and their comparisons with the experimental values for example 1

\begin{tabular}{|c|c|c|}
\hline Parameter & $\begin{array}{c}\text { (a) Min. } S E \text { \& } \\
\min V B 3\end{array}$ & $\begin{array}{c}\text { (b) Min. } S E \\
\& \max \\
\text { MRR }\end{array}$ \\
\hline$V_{\mathrm{c}}(\mathrm{m} / \mathrm{min})[$ optimized $]$ & 28 & 89 \\
\hline$w(\mathrm{~mm})[$ optimized $]$ & 2.8 & 3 \\
\hline$S E\left(\mathrm{~J} / \mathrm{mm}^{3}\right)[$ measured $]$ & 3.29 & 2.96 \\
\hline$V B 3\left(\mathrm{~mm}^{3}[\right.$ measured $]$ & 0.073 & 0.089 \\
\hline$M R R\left(\mathrm{~mm}^{3} / \mathrm{s}\right)[$ calculated $]$ & 184.7 & 623.5 \\
\hline
\end{tabular}

Table 3. The optimization results and their comparisons with the experimental values for example 2

\begin{tabular}{|c|l|l|}
\hline Parameter & (a) Min. VB3 & $\begin{array}{c}\text { (b) Min. SE } \\
\& \max \\
M R R\end{array}$ \\
\hline$V_{\mathrm{c}}(\mathrm{m} / \mathrm{min})$ [optimized] & 28 & 89 \\
\hline$f(\mathrm{~mm} / \mathrm{rev})[$ optimized $]$ & 0.07 & 0.17 \\
\hline$S E\left(\mathrm{~J} / \mathrm{mm}^{3}\right)[$ measured $]$ & 4.69 & 2.23 \\
\hline$V B 3\left(\mathrm{~mm}^{2}[\right.$ measured $]$ & 0.101 & 0.14 \\
\hline$M R R\left(\mathrm{~mm}^{3} / \mathrm{s}\right)[$ calculated $]$ & 115.5 & 883 \\
\hline
\end{tabular}

\section{Conclusions}

The article puts forward a fuzzy expert system used to upgrading a machining process for reduced energy consumption and tooling cost and enhanced productivity. The optimization objectives target the realistic needs of manufacturing industry and are in accordance with the sustainability principles.

Following pertinent conclusions can be drawn from the presented work:

1. Expert system, employing fuzzy reasoning, is a good tool to model highly complex manufacturing processes such as machining.
2. In order to slash energy demand of a cutting process, it is important to operate the process at high cutting speed and feed rate. Increase in width of cut is also helpful for this cause but with comparatively lower influence. This approach will also cause increase in productivity. Oppositely, high levels of the three cutting parameters cause rapid tool damage and increase in tooling cost.

\section{References}

1. M.F. Rajemi, P.T. Mativenga, A. Aramcharoen, J. Clean. Prod. 18, 1059-1065 (2010)

2. N. Diaz, E. Redelsheimer, D. Dornfeld, In: Globalized Solutions for Sustainability in Manufacturing. Springer Berlin Heidelberg. 263-267 (2011)

3. Q. Wang, F. Liu, X. Wang, Int. J. Adv. Manuf. Technol. 71, 1133-1142 (2014)

4. K.A. Al-Ghamdi, A. Iqbal, J. Clean. Prod. In press, doi:10.1016/j.jclepro.2015.05.132 (2015)

5. M. Arif, I.A.Stroud, O. Akten, Proc. Inst. Mech. Eng. (B): J. Eng. Manuf., 229, 266-274 (2014)

6. V.A. Balogun, P.T. Mativenga, J. Clean. Prod., 41, 179-186 (2013)

7. M.H.F. Al-Hazza, E.Y.T. Adesta, A.M. Ali, D. Agsman, M.Y. Suprianto, J. Appl. Sci., 11, 25782584 (2011)

8. K. Hashmi, I.D. Graham, B. Mills, J. Mat. Proc. Technol., 135, 44-58 (2003)

9. C.C. Tsao, H. Hocheng, J. Mat. Proc. Technol, 203, 342-348 (2008)

10. D.H. Ojha, U.S. Dixit, J.P. Davim, Int. J. Mat. \& Prod. Technol., 35, 145-166 (2009)

11. A. Iqbal, N.U. Dar, N. He, M.M.I. Hammouda, L. Li. J. Intel. Manuf. 21, 761-776 (2010) 